\title{
Strategi Pengembangan Agroforestri Dusung Di Negeri Hative Besar, Kecamatan Teluk Ambon, Kota Ambon
}

\author{
Niny Jeni Maipauw ${ }^{1}$, M. Silaya ${ }^{2}$, R. Loppies ${ }^{2}$ \\ ${ }^{1}$ Universitas Muhammadiyah Sorong \\ ${ }^{2}$ Universitas Pattimura Ambon \\ ninyjenimaipauw@gmail.com
}

\begin{abstract}
Abstrak
Agroforestry adalah pendekatan terintegrasi memanfaatkan interaksi pohon dan belukar dengan tanaman pertanian. Agroforestry menggabungkan teknologi pertanian dan kehutanan untuk menciptakan kondisi yang lebih beranekaragam, produktif, sehat, menguntungkan dan system penggunaan lahan yang lestari. Penelitian ini bertujuan untuk mengetahui faktor-faktor apa saja yang mempengaruhi pengembangan agroforestry dan strategi pengembangan di Negeri Hative Besar, Kecamatan Teluk Ambon Kota Ambon. Metode penelitian ini adalah metode survey dan wawancara. Data yang diperoleh melalui pengamatan langsung dan quisioner. Metode analisis adalah kuantitatif dan kualitatif. Hasil penelitian menunjukkan faktor-faktor yang mempengaruhi pengembangan agroforestry dusung adalah vegetasi pohon, tanaman pangan, tanaman tahunan, sosial ekonomi petani, pengelolaan lahan tradisional yang disebut dusung. Penerapan dan pengembangan agroforestry dilakukan melalui analisis SWOT.
\end{abstract}

Kata kunci: Pengembangan Agroforestri, Negeri Hative Besar

\section{PENDAHULUAN}

Hutan merupakan salah satu sumber daya alam, sebagai anugerah Tuhan yang perlu disyukuri oleh manusia untuk dikelola, dimanfaatkan, dan dilestarikan. Hutan juga merupakan sumber daya alam yang dapat diperbaharui dan merupakan bagian dari ekosistem tempat berlangsungnya hubungan timbal balik antara manusia dengan faktorfaktor lingkungan yang mempengaruhinya. Berdasarkan UU No 41 Tahun 1999 Hutan didefenisikan sebagai hamparan lahan yang berisi sumber daya alam yang didominasi oleh pepohonan yang saling berkaitan dan mempunyai hubungan timbal balik satu dengan lainnya sehingga tidak dapat di pisahkan. Hutan memegang peran penting dalam kehidupan baik sebagai pemenuhan kebutuhan hidup maupun sebagai pencegah bahaya banjir, erosi, kekeringan, serta manfaat lainnya berupa hasil kayu maupun non kayu dan tanaman obat-obatan.seiring berputarnya waktu maka pengembangan hutan saat ini dipengaruhi oleh meningkatnya jumlah penduduk beserta segala aktivitasnya guna memenuhi kebutuhan yang semakin kompleks.

Agroforestri adalah sebuah istilah yang baru dikemukakan pada tahun 1970 tapi prakteknya sudah lama dilakukan oleh masyarakat dengan berbagai fungsi yang dirasakan oleh masyarakat. Keunggulan dari agroforestri dusung adalah multi jenis, 


\section{Median Volume 12 Nomor 1 Bulan Februari 2020}

multi strata tajuk, kesinambungan vegetasi dan penggunaan bentang lahan dari penelitian terdahulu (Hariah dkk 2003 dalam ICRAF).

Masyarakat sebagai bagian dari ekosistem itu sendiri berperan aktif dalam pengelolaan hutan serta bertanggung jawab masyarakat di Maluku dalam pengelolaan hutan adalah mencegah pengurangan luas kawasan hutan dengan melaksanakan atau menerapkan pola dusung (agroforesri tradisional). Pola dusung sudah ada sejak dahulu kala dan merupakan suatu tradisi yang masih ada dan tetap dipertahankan berdasarkan pengalaman dan kearifan lokal masyarakat. Menurut Markus (2014), selain melestarikan ekosistem dusung dapat dianggap sebagai bank petani di beberapa pulau terpencil.

Istilah dusung dalam penerapannya baik dalam bentuk lisan maupun tertulis sering berbeda diantara negeri yang satu dengan yang lain dan disesuaikan (sesuai daerah setempat). Ada yang menyebutnya dusung, dusun, dusong, dan arti dusung oleh masyarakat Maluku adalah bentuk pemanfaatan lahan pertanian yang berbeda dengan dusun yang dimaksud sebagai anak desa dalam struktur administrasi pemerintah desa.

Manfaat dari pengembangan dusung tersebut memberikan suatu perubahan bagi masyarakat dan lingkungan, kearah yang lebih baik dengan terpenuhinya kebutuhan jangka pendek, menegah, dan panjang sehingga masyarakat dapat terus mempertahankan hidup dengan mengelola sumber daya. Diperlukan manejemen yang baik agar fungsi produksi, fungsi konservasi maupun social, ekonomi, budaya, dan aturan-aturan yang berlaku untuk mengatur hasil-hasil dusung dapat dikembangkan. (Sahureka, 2018 dan Patoding, dkk, 2018).

Salah satu desa atau negeri di pulau Ambon yang memiliki dusung dengan berbagai keanekaragaman vegetasi di dalamnya serta memberikan manfaat yang penting adalah negeri hative Besar. Pada umumnya mata pencaharian masyarakat negeri Hative Besar adalah sebagai petani, sedangkan mata pencaharian sampingannya adalah nelayan, tukang kayu, pedagang, tukang ojek, dan peternak.

Masyarakat negeri Hative Besar memiliki banyak dusung sehingga dikelola untuk pemenuhan kebutuhan keluarga sehari-hari, serta ada juga hasil yang dijual. Kebanyakan hasil yang dijual berupa buah-buahan, Sesuai musim buah yang berlaku pada negeri Hative Besar.

Perlu dilakukan penelitian tentang pentingnya strategi pengembangan dusung pada negeri Hative Besar. Berdasarkan permasalah tersebut, maka tujuan dari penelitian ini adalah untuk mengetahui faktor-faktor yang mempengaruhi pengembangan agroforestri dusung di negeri Hative Besar dan strategi pengembangan dusung di negeri Hative Besar.

\section{METODE PENELITIAN}

Metode yang digunakan adalah metode survey langsung dan wawancara kepada masyarakat, di mana diperoleh melalui pengamatan langsung dilapangan dan pengisian quisioner. Metode penentuan sampel menggunakan purposive sampling dimana sampel 


\section{Median Volume 12 Nomor 1 Bulan Februari 2020}

yang diambil berdasarkan beberapa pertimbanngan yaitu: pemilik dusung, tokoh masyarakat atau kepala desa, tokoh masyarakat adat (Kewang), kepala keluarga (KK).

Pengambilan sampel ini dilakukan dengan mengambil data kepala keluarga atau penduduk asli sebagai pemilik dusung di negeri Hative Besar sebanyak 10\% dari jumlah kepala keluarga yang ada.

\section{Metode pengumpulan data.}

Data yang diperlukan dalam penelitian ini adalah data primer dan data sekunder. Data primer adalah data yang diperoleh langsung dari hasil wawancara dengan responden dan pengamat dilapangan. Sedangkan data sekunder adalah data yang diperoleh dari hasil penelitian sebelumnya oleh instansi-instansi terkait atau literaturliteratur yang berhubungan dengan penelitian ini. Adapun metode yang digunakan untuk pengumpulan data dalam penelitian ini adalah antara lain:

1. Observasi (pengamatan) : yaitu pengumpulan data dengan mengamati dan mencatat secara sistematik gejala-gejala yang sesuai dengan kajian penelitian.

2. Wawancara yaitu melakukan tanya jawab secara lisan

3. Analisis vegetasi.

Metode pengamatan yang dilakukan menggunakan jalur pengamatan dengan panjang jalur 700 meter dan lebar 20 meter. Kriteria alam pengamatan vegetasi di lapangan adalah sebagai berikut:

a. Tingkat pohon dengan diameter $>20 \mathrm{~cm}$ ukuran petak 20x20 M

b. Tingkat tiang dengan diameter $10-19 \mathrm{~cm}$ ukuran petak $10 \times 10 \mathrm{M}$

c. Tingkat pancang dengan diameter $10 \mathrm{~cm}$ tinggi 1,5-3 $\mathrm{m}$ ukuran petak $5 \times 5 \mathrm{M}$

d. Tingkat semai dengan tinggi tumbuhan $0-1,5 \mathrm{~cm}$ ukuran petak $2 \times 2 \mathrm{M}$

\section{Metode Analisis data}

1. Analisis vegetasi

Berdasarkan data hasil analisis vegetasi diketahui kekayaan jenis yang ada dikawasan tersebut, kemudian setiap jenis vegetasi dihitung kerapatan (K), kerapatan relative (KR), frekuenis (F), frekuensi relative (FR), dominansi (D), dominasi relative (DR) dan indeks nilai penting.

2. Analisis SWOT

Menurut Rangkuti, 2006, Analisis SWOT adalah salah satu langkah yang paling penting dalam memformulasikan strategi. Tujuannya adalah untuk mengembangkan strategi yang baik yang mengeksploitasi peluang dan kekuatan, menetralisir ancaman dan menghindari kelemahan. 
Tabel 1. Matriks Analisis SWOT

\begin{tabular}{|c|c|c|}
\hline $\begin{array}{l}\text { Faktor Internal (IFAS) } \\
\text { Faktor Eksternal (EFAS) }\end{array}$ & $\begin{array}{l}\text { STRENGTH (S) } \\
\text { Faktor Kekuatan }\end{array}$ & $\begin{array}{l}\text { WEAKNESS (W) } \\
\text { Faktor Kelemahan }\end{array}$ \\
\hline $\begin{array}{l}\text { OPPORTUNITIES (O) } \\
\text { Faktor Peluang }\end{array}$ & $\begin{array}{c}\text { STRATEGI (S-O) } \\
\text { Ciptakan strategi yang } \\
\text { menggunakan kekuatan untuk } \\
\text { memanfaatkan peluang }\end{array}$ & $\begin{array}{c}\text { STRATEGI (W-O) } \\
\text { Ciptakan strategi yang } \\
\text { meminimalkan kelemahan } \\
\text { untuk memanfaatkan peluang }\end{array}$ \\
\hline $\begin{array}{l}\text { TREATHS (T) } \\
\text { Faktor Ancaman }\end{array}$ & $\begin{array}{c}\text { STRATEGI (S-T) } \\
\text { Ciptakan strategi yang } \\
\text { menggunakan kekuatan untuk } \\
\text { mengatasi ancaman }\end{array}$ & $\begin{array}{c}\text { STRATEGI (W-T) } \\
\text { Ciptakan strategi yang } \\
\text { meminimalkan kelemahan dan } \\
\text { menghindari ancaman }\end{array}$ \\
\hline
\end{tabular}

Catatan: dari tabel 1 dapat dilihat strategi apa yang memberikan nilai pengaruh yang paling besar.

\section{HASIL DAN PEMBAHASAN}

Berdasarkan hasil penelitian yang dilakukan, adapun faktor-faktor yang mempengaruhi pengembangan agroforestry terdiri dari:

\section{Vegetasi dalam dusung}

Dari hasil penelitian di negeri Hative Besar menunjukan bahwa di dalam dusung terdapat 26 jenis vegetasi yang terdiri dari berbagai tingkatan yaitu : tingkat pohon 21 jenis, tiang 19 jenis, pancang 17 jenis dan semai 19 jenis.

Tabel 2. Tingkat pertumbuhan vegetasi dalam dusung di negeri Hative Besar

\begin{tabular}{|c|c|c|}
\hline No & $\begin{array}{c}\text { Tingkat } \\
\text { Pertumbuhan }\end{array}$ & Jenis /spesies \\
\hline 1 & Pohon & $\begin{array}{l}\text { Eugenia aromatica, Cocos nusifera, Arthocarpus cempeden, Parkia } \\
\text { speciosa, Durio zibethinus, Langsium domesticum correa, Manggifera } \\
\text { embacan, Boueva macrophylla,Garcinia mangostana, Langsium } \\
\text { domesticum, Canarium commune, Albizia parasirianthes, Pteocarpus } \\
\text { indica, Casuarina equistifolia, Dracontomelon dao, Myristica fragrans, } \\
\text { Ceiba petandra, Arthocepalus macrophylus, Terminalia catapa, Inocarpus } \\
\text { fagiferus, Spondias pinnata,. }\end{array}$ \\
\hline 2 & Tiang & $\begin{array}{l}\text { Eugenia aromatica, Cocos nusifera, Arthocarpus cempeden, Durio } \\
\text { zibethinus, Langsium domesticum correa, Manggifera embacan, Garcinia } \\
\text { mangostana, Langsium domesticum, Albizia parasirianthes, Pteocarpus } \\
\text { indica, Casuarina equistifolia, Dracontomelon dao, Arthocepalus } \\
\text { macrophylus,Arthocarpus integra, Gnetum gnemon, Mangifera fudita, } \\
\text { Nephelium lappeceum, Gmelina moluccana. }\end{array}$ \\
\hline 3 & Pancang & $\begin{array}{l}\text { Eugenia aromatica, Arthocarpus cempeden, Parkia speciosa, Langsium } \\
\text { domesticum correa, Manggifera embacan, Boueva macrophylla,Garcinia } \\
\text { mangostana, Langsium domesticum, Albizia parasirianthes, Pteocarpus } \\
\text { indica, Casuarina equistifolia, Dracontomelon dao, Myristica fragrans, } \\
\text { Arthocepalus macrophylus, Gnetum gnemon, Mangifera fudita, } \\
\text { Nephelium lappeceum, }\end{array}$ \\
\hline 4 & Semai & $\begin{array}{l}\text { Eugenia aromatica, Arthocarpus cempeden, Parkia speciosa, Durio } \\
\text { zibethinus, Langsium domesticum correa, Boueva macrophylla,Garcinia } \\
\text { mangostana, Langsium domesticum, Albizia parasirianthes, Casuarina } \\
\text { equistifolia, Dracontomelon dao, Myristica fragrans, Ceiba petandra, } \\
\text { Arthocepalus macrophylus , Arthocarpus integra, Gnetum gnemon, } \\
\text { Mangifera fudita, Nephelium lappeceum }\end{array}$ \\
\hline
\end{tabular}

Sumber: Data primer 


\section{Median Volume 12 Nomor 1 Bulan Februari 2020}

Doi http://doi.org/md.v12i1.831

Tabel 3 Indeks Nilai Penting jenis vegetasi dusung di negeri Hative Besar

\begin{tabular}{clcccc}
\hline \multirow{2}{*}{ No } & \multicolumn{2}{c}{ Nama Jenis Vegetasi } & \multicolumn{5}{c}{ Tingkatan } \\
\cline { 3 - 6 } 1 & Eugenia aromatica & 13.83 & 19.79 & 9.00 & 6.37 \\
2 & Cocos nusifera & 16.08 & 9.63 & - & - \\
3 & Arthocarpus cempeden & 21.79 & 6.31 & 9.43 & 6.17 \\
4 & Parkia speciosa & 13.27 & - & 13.40 & 10.40 \\
5 & Durio zibethinus, & 13.69 & 10.18 & - & 10.99 \\
6 & Langsium domesticum correa & 12.09 & 28.02 & 15.05 & 13.18 \\
7 & Manggifera embacan, & 11.83 & 8.14 & 10.01 & - \\
8 & Boueva macrophylla & 11.26 & - & 8.34 & 9.73 \\
9 & Garcinia mangostana & 23.69 & 13.29 & 13.54 & 9.01 \\
10 & Langsium domesticum & 9.75 & 9.00 & 15.82 & 14.29 \\
11 & Canarium commune & 31.76 & - & - & - \\
12 & Albizia parasirianthes, & 12.71 & 7.22 & 10.01 & 7.84 \\
13 & Pteocarpus indica & 10.68 & 10.89 & 9.00 & - \\
14 & Casuarina equistifolia & 14.42 & 6.82 & 12.31 & 7.21 \\
15 & Dracontomelon dao & 11.70 & 7.22 & 7.54 & 10.99 \\
16 & Myristica fragrans & 21.50 & - & 9.43 & 13.50 \\
17 & Ceiba petandra & 13.07 & - & - & 8.74 \\
18 & Arthocepalus macrophylus & 7.73 & 10.18 & 8.94 & 9.88 \\
19 & Terminalia catapa & 6.91 & - & - & - \\
20 & Inocarpus fagiferus & 12.39 & - & - & - \\
21 & Spondias pinnata & 7.73 & - & - & - \\
22 & Arthocarpus integra & - & 6.31 & - & 10.40 \\
23 & Gnetum gnemon & - & 9.46 & 8.94 & 15.31 \\
24 & Mangifera fudita & - & 9.06 & 11.43 & 12.55 \\
25 & Nephelium lappeceum & - & 7.22 & 7.54 & 13.27 \\
26 & Gmelina moluccana & 9.46 & - & - \\
\hline & & & & &
\end{tabular}

Sumber: Data primer

Menurut odum (1971) dalam Soenaryo (2004), menyatakan bahwa semakin besar INP suatu jenis maka jenis tersebut sangat stabil pertumbuhan pada ekositem tersebut karena didukung oleh faktor- faktor tempat tumbuhnya. Oleh karena itu jenis-jenis yang nilai pentingnya semakin tinggi cenderung memiliki kemampuan yang lebih besar dari jenis lainnya. Indeks Nilai Penting suatu spesies sangat dipengaruhi oleh beberapa faktor antara lain kerapatan, penyebaran dan dominansi spesies dimana spesies-spesies yang menyebar secara luas mempunyai kerapatan frekuensi dan dominansi spesies yang tinggi.

\section{Aspek social dalam pengelolaan dusung}

Dalam kehidupan masyarakat di lokasi penelitian terdapat sejumlah nilai social budaya atau tradisi yang mengatur hubungan antara masyarakat satu dengan 


\section{Median Volume 12 Nomor 1 Bulan Februari 2020}

yang lainnya. Nilai social budaya ini merupakan wujud dari kearifan masyarakat dalam menjaga keserasian dan keharmonisan, nilai-nilai tersebut diantaranya adalah gotong royong atau masohi. Pada lokasi penelitian ditemukan ada tiga jenis dusung yang dilihat dari segi kepemilikannya. Bentuk dusung yang ditemukan adalah Dusung Raja, Dusung Negeri Dan Dusung Dati.

\subsection{Dusung Raja}

Dusung Raja adalah dusung yang kepemilikiannya diperuntukan bagi raja dan digunakan untuk kepentingan dan kehidupan raja. Seorang raja akan kehilangan haknya atas dusung tersebut apabila ia diganti dan dusung ini tidak dapat diwariskan kepada turunan raja melainkan diberikan kepada raja yang baru. Hasil penelitian menunjukan dusung raja masih di berlakukan sampai sekarang ini mereka masih mempertahankan keberadaan dusung tersebut sebagai 'Dusung Parintah' yang berasal dari kata "pemerintah". Penyebabnya masih bertahan dusung raja pada daerah penelitian adalah regenerasi raja (Kepala Desa) masih bersifat keturunan sehingga pewarisan masih tetap dari raja yang lama kapada anaknnya atau saudara sebagai raja yang baru . ini juga yang membedakan negeri Hative Besar dengan negeri-negeri yang lain, dimana pergantian raja tidak selamanya dari ayah kepada anak (keturunan).

\subsection{Dusung Negeri}

Dusung Negeri adalah dusung yang dimiliki oleh negeri dan diatas dusung ini terdapat berbagai jenis tanaman. penduduk negeri tidak diperkenankan untuk mengambil hasil atas dusung tersebbut. Dusung ini ada yang sering dilelang atau disewakan dan hasilnya dimasukan kedalam kas negeri. Dusung Negeri masih ada sampai sekarang dan diawasi oleh kewang. Dusung negeri merupakan pemberian dari keluarga yang dulunya sudah tidak lagi memiliki keturunan untuk diwariskan sehingga mereka memberikan dusung mereka kepada negeri dan dijadikan sebagai dusung negeri. Dusung negeri ini pernah dibagikan kepada keluarga yang kurang mampu dan yang berjasa bagi negeri untuk dijadikan sebagai lahan usaha mereka dan hasil dibagi dua sebagian untuk masyarakat yang mengelola dan sebagian lagi ke dalam kas negeri.

\subsection{Dusung Dati}

Dusung dati adalah dusng pewarisan keluarga untuk anak laki-laki yang membawa nama marga yang berada dalam tanah dati. Dusung dati merupakan dusung milik keluarga yang dikelola oleh masing-masing keluarga, namun dalam pengelolaan dusung, kewang mempunyi hak sepenuhnya untuk mengawasi kegiatan dari para pemilik dusung berkaitan dengan batas-batas lahan dan kegiatan penebangan.

Secara tradisional dusung dati merupakan dusung yang diwariskan sepenuhnya kepada anak laki - laki yang membawa nama marga. Namun kenyataan pada lokasi penelitian ada orang tua yang membagi dusungnya kepada anak perempuan karena 


\section{Median Volume 12 Nomor 1 Bulan Februari 2020}

Doi http://doi.org/md.v12i1.831

tidak memiliki anak laki-laki atau diberikan kepada anak perempuan sebagai pengasihan dari orang tua kepada anak perempuan yang tidak memiliki pekerjaan ataupun suami dari si anak yang tidak memiliki pekerjaan.

\section{Aspek Ekonomi dalam pengelolaan dusung}

Dusung merupakan sumber pendapatan yang potensial bagi ekonomi keluarga / masyarakat. Hasil analisis ekonomi kontribusi dusung bagi pendapatan keluarga dilokasi penelitian menunjukan bahwa dari berbagai jenis tanaman yang ada didalam dusung diperoleh rata-rata pendapatan keluarga selama setahun $\mathrm{Rp}$ 20.713.000 atau 70,74\% dari total pendapatan. Keluarga dalam setahun dari hasil dusung adalah $\mathrm{Rp}$ 14.560.000 hal ini menunjukan bahwa dalam bidang ekonomi dusung dapat meningkatkan kesejahtraan keluarga. Hal ini sesuai dengan Siwelette (2018) dan Sahureka \& Talaohu (2018) yang menyatakan bahwa agroforestry dusung memberikan manfaat dari segi ekonomi bagi masyarakat di beberapa wilayah.

\section{Aspek Manajemen dalam pengelolaan dusung}

Dusung sebagai suatu bentuk agroforestri jika dikelola dengan baik akan memberikan manfaat yang besar, baik manfaat social ekonomi maupun manfaat ekologi bagi masyrakat. (Sabar, 2002). Menurut Salampessy (2012), Dusung memiliki aspek dalam hal pembangunan ekonomi, lingkungan dan manajemen yang berperan sangat penting untuk pengembangan kinerja dusung itu sendiri (produktivitas, keberlanjutan, kesetaraan dan manfaat efisiensi). Prinsip - prinsip umum yang menjadi landasan dalam merumuskan manajemen atau pengelolaan dusung yaitu :

1. Dusung bertujuan untuk memelihara dan meningkatkan keunggulan-keunggulan sehingga dapat mewujudkan kelestarian sumber daya alam serta meningkatkan kesejahtraan masyarakat.

2. Rumusan manajemen dusung adalah beberapa jenis vegetasi tetapi memenuhi kriteria :

a. Campuran jenis tanaman tahunan / pohon-pohonan (kehutanan) dan tanaman semusim/pangan (pertanian)

b. Beberapa strata tajuk

c. Produktivitas cukup baik dan memberi pendapatan yang baik bagi masyarakat.

d. Terjaga kelestarian ekosistem yakni adanya kesinambungan vegetasi.

e. Dapat diadopsi dan dilaksanakan oleh masyarakat.

3. kerja sama antara masyarakat / petani pemilik dusun, dalam upaya menatasi masalah. Aspek manajemen atau pengelaloaan dusung dapat dilakukan melalui:

a. Manajemen produksi: penanaman, pemeriharaan, penyulaman, pemanenan.

b. Pemasaran: pengeturan hasil panen dan pemasaran hasil panen

c. Penanganan / pengolahan pasca panen

Bentuk konservasi tradisional masyarakat pedesaan di daerah Maluku yang telah lama diterapkan pada kawasan darat telah memberikan fungsi-fungsi jasa 


\section{Median Volume 12 Nomor 1 Bulan Februari 2020}

lingkungan dan nilai ekonomi yang diperoleh pengelolaan adalah system dusung. Pengelolaan dusung umumnya dilakukan secara tradisional dan tidak menggunakan teknologi atau alat yang canggih mulai dari penggunaan lahan, penanaman, pemeliharaaan, penyulaman, sampai pada pemanenan. Dengan sistem dusung yang digunakan dalam masyarakat maka kerusakan hutan sangat kecil karena masing masing pemilik dusung menjaga dan melestarikan sumber daya alam yang ada dalam dusung baik tanaman pohon- pohon di jaga oleh pemilik dusung (Ajawailla 1996). Hal senada juga disampaikan Mulyana (2017) bahwa Performa pengelolaan agroforestry sangat dipengaruhi oleh sistem pengelolaan hutannya, baik dari segi penguasaan lahan maupun hasil hutan yang dikuasai secara individu.

\section{Faktor internal dan eksternal dalam pengembangan Dusung di negeri Hative Besar}

\section{1) Faktor Internal}

Analisis faktor strategi internal adalah analisis yang menilai prestasi/kinerja yang merupakan faktor kekuatan dan kelemahan yang ada untuk mencapai tujuan organisasi. Data internal dapat diperoleh di dalam organisasi seperti sarana prasarana, jumlah sumber daya manusia (SDM), keuangan dan operasional lainnya (Rangkuti 2006).

A. Kekuatan (Strengths)

Faktor -faktor yang menjadi kekuatan adalah:

a) Tanaman yang ditanam beragam jenis di dalam dusung dengan 26 jenis vegetasi

b) Tanaman yang ditanam beragam dan biasanya bernilai ekonomi tinggi (banyak laku) dipasar seperti buah-buahan.

c) Hasil dusung memberikan kontribusi terbesar bagi pendapatan keluarga.

d) Jarak dari negeri Hative Besar ke dusung beragam tergantung ada dari $1 \mathrm{~km} \mathrm{-} 4$ $\mathrm{km}$

e) Luas dusung yang dimiliki oleh petani di Negeri Hative Besar beragam, ada yang memiliki luas dusun $1 \mathrm{Ha}$ sampai $5 \mathrm{Ha}$

f) Meningkatkan sasi

B. Kelemahan (Weakness)

Faktor-faktor yang menjadi kelemahan adalah:

a) Jenis tanaman dalam dusung belum ditata dengan baik

b) Belum adanya pemenfaatan lahan secara optimal

c) Kurangnya pengetahuan masyarakat dalam pemanfaatan hasil hutan.

d) Topografi yang berbukit-bukit.

\section{2) Faktor eksternal}

Analisis faktor strategi difokuskan pada kondisi yang ada dan kecendrungan yang muncul dari luar, tetapi dapat member pengaruh kinerja organisasi. Data eksternal ini diperoleh dari lingkungan diluar organisasi seperti: analisis pasar, analisis competitor, analisis komunitas dan analisis pemerintah/ stakeholder lain (Rangkuti, 2006). 


\section{Median Volume 12 Nomor 1 Bulan Februari 2020}

Doi http://doi.org/md.v12i1.831

\section{A. Peluang (Opportunities)}

Faktor-faktor yang menjadi peluang adalah:

a) Akses pasar lancer dan didukung oleh prasarana jalan yang baik

b) Adanya program pemerintah dalam rehabilitasi lahan

c) Diversifikasi produk buah

B. Ancaman (threats)

a) Penurunan kualitas lingkungan akibat global yang semakin meningkat

b) Konversi lahan dusung ke bentuk penggunaan lain akibat pertambahan penduduk.

\section{3) Matriks Analisis SWOT}

Tabel 4. Matriks Analisis SWOT Strategi Pengembangan dusung.

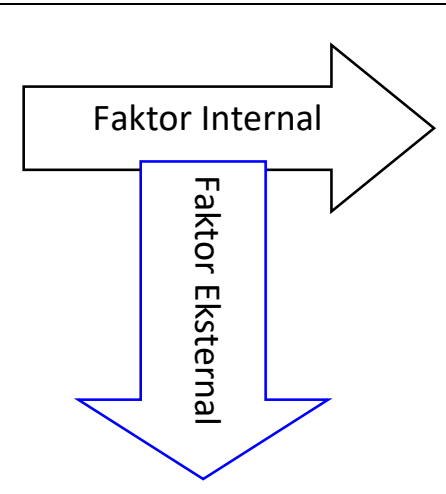

Peluang

1. Akses pasar lancer dan didukung oleh prasarana jalan yang baik

2. Adanya program pemerintah dalam rehabilitasi lahan

3. Diversifikasi produk buah

\section{Kekuatan}

1. Berbagai jenis tanaman di dalam dusung

2. Jenis tanaman bernilai ekonomi tinggi (laku di pasar)

3. Hasil dusung memberikan kontribusi bagi pendapatan

4. Jarak dusung dekat

5. Luas dusung mempengaruhi

6. Sasi
Kelemahan

1. Jenis tanaman dalam dusung belum ditata dengan baik

2. Belum adanya pemenfaatan lahan secara optimal

3. Kurangnya pengetahuan masyarakat dalam pemanfaatan hasil hutan.

4. Topografi yang berbukitbukit

Strategi (WO)

1. Pengembangan pemasaran hasil-hasil Dusung dalam bentuk peningkatan produksi yang dipasarkan.

2. Peningkatan aksesibilitas

1. Peningkatan optimalisasi pemanfaatan lahan melalui program pemerimtah (rehabilitasi lahan)

2. Pengaturan jenis tanaman dalam dusung agar terjadi peningkatan produksi yang akan dipasarkan.

\section{Ancaman}

1. Penurunan lingkungan akibat global yang semakin meningkat

2. Konversi lahan dusung ke bentuk penggunaan lain akibat pertambahan penduduk.

\section{Strategi (ST)}

1. Pengembangan jenis- jenis tanaman didalam dusung untuk mengatasi penurunan kualitas lingkungan.

2. Perluasan areal Dusung melalui pembukaan lahan baru disekitar dusung.

\section{Strategi (WT)}

1. Peningkatan kualitas lingkungan melalui penataan dalam dusung dan optimalisasi pemanfaaatan lahan.

Berdasarkan tabel 4, maka ada dua strategi alternatif yang dapat digunakan yaitu:

A. Strategi SO ( Strengths and Opportunities) yaitu : strategi yang mengoptimalkan kekuatan untuk memanfaatkan peluang. 


\section{Median Volume 12 Nomor 1 Bulan Februari 2020}

Doi http://doi.org/md.v12i1.831

a) Pengembangan pemasaran hasil -hasil dusung dalam bentuk peningkatan produksi yang akan dipasarkan.

Pemasaran hasil-hasil dusung yang akan dipasarkan beragam ada beberapa buah segar seperti langsa, duku, rambutan, manggis, durian, gandaria, nenas. Ada beberapa buah-buahan yang sudah olah menjadi minimum seperti gandaria dan nenas ada yng dibuat asinan. Sehingga boleh dipasarkan dengan beragam harga yang akan ditawarkan kepada pelanggan yang berminat sehingga menambah pendapatan bagi para petani.

b) Peningkatan aksesibilitas

Dengan bermobilisasi menggunakan transportasi darat baik berupa mobil dan motor, didukung sarana jalan yang sudah bagus dan lancar sehingga dengan mudah akan sampai ke pasar dan mudah untuk mendapatkan buah-buahan yang masih segar untuk di konsumsi.

B. Strategi WO (Weaknesses and Opportunities) yaitu strategi yang meminimalkan kelemahan untuk memanfaatkan peluang .

a) Peningkatan optimalisasi pemanfaatan lahan melalui program pemerintah rehabilitasi lahan).

Adanya bantuan pemerintah berupa program peternakan sehingga membuat para petani kembali lagi bias beraktivitas didusung berupa ternak ayam, sapi, dan alat pertanian yang diberikan kepada para petani sehingga mereka merasa diperhatikan. Program yang dibuat pemerintah membantu mereka untuk menambah penghasilan.

b) Pengaturan jenis tanaman dalam dusung agar terjadi peningkatan produksi yang bisa dipasarkan.

Pengaturan jenis- jenis tanaman dalam dusung agar tidak terjadi persaingan unsure hara dan boleh di pungut hasilnya sesuai dengan waktu panen baik dalam waktu beberapa bulan atau tahun dan bisa memperoleh hasil yang selalu diinginkan dan dipasarkan.

c) Strategi ST (Strenghts and Threats) yaitu strategi yang menggunakan kekuatan untuk mengatasi ancaman.

d) Pengembangan jenis-jenis tanaman didalam dusung untuk mengatasi penurunan kualitas lingkungan.

Banyak vegetasi di dalam dusung sehingga memiliki banyak dampak positif seperti : mencegah banjir, tanah longsor, serta erosi, memperbaiki struktur tanah, menambah seresah bagi tanah baik tanaman musiman atau tahunan.

e) Perluasan daerah dusung melalui pembukaan lahan baru disekitar dusung dari alang-alang.

Daerah sekitar areal dusung ada alang-alang yang tumbuh sehingga bisa dibersihkan kembali dan di kelola agar daerah dusung lebih 


\section{Median Volume 12 Nomor 1 Bulan Februari 2020}

Doi http://doi.org/md.v12i1.831

luas dan bisa memberikan hasil yang lebih banyak bagi para petani sesuai dengan jenis-jenis tanaman yang akan dikelola.

f) Strategi WT (Weaknesses and Threats) yaitu : strategi yang meminimalkan kelemahan dan menghindari ancaman.

g) Peningkatan kualitas lingkungan melalui penataan dalam dusung dan optimalisasi pemanfaatan lahan.

Kualitas lingkungan perlu dijaga karena sangat mempengaruhi keadaan sekitar dusung. Lahan yang kurang produktif harus diistirahatkan atau didiamkan selama beberapa tahun barulah dikelola kembali untuk memperbaiki unsur-unsur hara di dalam tanah baik unsur hara mikro maupun makro. Sehingga beberapa tahun kemudian lahan tersebut sudah bisa di kelola kembali.

\section{KESIMPULAN}

Adapun kesimpulan yang diperoleh dari penelitian ini adalah:

1. Faktor-faktor yang mempengruhi pengembangan dusung adalah : berbagai jenis vegetasi di dalam dusung, faktor sosial ekonomi masyarakat, aspek pengolahan dusung berupa pembukaan lahan, pembersihan, penanaman, pemeliharaan dan pemungutan hasil.

2. Pengembangan dusung memiliki beberapa strategi yaitu:

a. Pengembangan pemasaran hasil-hasil dusung dalam bentuk peningkatan produksi yang dipasarkan.

b. Peningkatan optimalisasi pemanfaatan lahan melalui program pemerintah (rehabilitasi lahan)

c. Pengembangan jenis-jenis tanaman di dalam dusung untuk mengatasi penurunan kualitas lingkungan.

d. Peningkatan kualitas lingkungan melalui penataan dalam dusung dan optimalisasi pemanfaatan lahan.

\section{DAFTAR PUSTAKA}

Ajawailla. J .W 1996 Potensi Sosial Budaya Agroforestri Dusung. Pusat Studi Maluku Universitas Pattimura Ambon

Hairiah K., dkk. 2003. Bahan Ajar Agroforestri L. Icraf. Bogor.

Markus, M.J. 2014. A Review on Dusun as an Indigenous Agroforestry System Practiced in Small Islands. New Horizon of Island Studies in the Asia-Pacific Region (54), 53-60.

Mulyana, L. 2017. Performa Pengelolaan Agroforestri Di Wilayah KPHL Rajabasa. [Skripsi]. Fakultas Pertanian, Universitas Lampung.

Patoding, N., Matinahoru, J., \& Mardiatmoko, G. (2018). Analisis Strategi Pengembangan Agroforestri Berdasarkan Rancangan Teknis Iuphkm Di Dusun 


\section{Median Volume 12 Nomor 1 Bulan Februari 2020}

Doi http://doi.org/md.v12i1.831

Melinani, Desa Manusela, Kabupaten Maluku Tengah. Jurnal Hutan Pulau-Pulau

Kecil, 2(1), 70-90. https://doi.org/10.30598/jhppk.2018.2.1.70

Rangkuti F. 2006. Analisis Swot Teknik Membedahkan Kasus Bisnis. Jakarta PT Gramedia Pustaka

Salampessy, L. M., Bone, I., dan Febryano, I.G. 2012. Performansi Dusung Pala sebagai Salah Satu Agroforestry Tradisional di Maluku. TENGKAWANG Jurnal Ilmu Kehutanan, 2(2): 55-65. http://dx.doi.org/10.26418/jt.v2i2.1941

Sabar. M. S. 2002. Prinsip Produktivitas Keserbangunan Pohon Dan Interaksi Antara Komponen Laboratorium Agroforestri. Fakultas Kehutanan Universitas Gajah Mada Yogyakarta

Sahureka. 2018. Konsep Manejemen Pengelolaan Dan Pengembangan Agroforestri Tradisionl (Dusung). Jurnal Agrohut, 9(1): 23-30.

Sahureka, M., \& Talaohu, M. 2018. Pengelolaan Agroforestry Tradisional "Dusung” Berbasis Kearifan Lokal "Masohi" Oleh Masyarakat Desa Hulaliu-Kabupaten Maluku Tengah. Jurnal Hutan Pulau-Pulau Kecil, 2(2), 138-148. https://doi.org/10.30598/jhppk.2018.2.2.138

Siwalette, J. D. 2018. Transformation of Production Organization of Dusung based Nutmeg Plantation (Case Study of Industrial and Farmers' Partnership in Hila Village, Moluccas Province). Advances in Social Sciences Research Journal, 5(3). https://doi.org/10.14738/assrj.53.4248

Soenaryo. 2004. Perilaku Organisasi. Yogyakarta. Grafika Indah. 